Article

\title{
Optimum Sizing of Photovoltaic-Battery Power Supply for Drone-Based Cellular Networks
}

\author{
Mahshid Javidsharifi ${ }^{1, *(D)}$, Hamoun Pourroshanfekr Arabani ${ }^{2}$, Tamas Kerekes ${ }^{1} \mathbb{D}$, Dezso Sera ${ }^{3}$, \\ Sergiu Viorel Spataru 4 (D) and Josep M. Guerrero ${ }^{5}$ (D)
}

1 Department of AAU Energy, Aalborg University, 9220 Aalborg, Denmark; tak@energy.aau.dk

2 Division of Industrial Electrical Engineering and Automation, Lund University, SE-22100 Lund, Sweden; hamoun.pourroshanfekr_arabani@iea.lth.se

3 Faculty of Engineering, Queensland University of Technology, Brisbane, QLD 4000, Australia; dezso.sera@qut.edu.au

4 Department of Photonics Engineering, Technical University of Denmark, 4000 Roskilde, Denmark; sersp@fotonik.dtu.dk

5 Center for Research on Microgrids (CROM), Department of Energy Technology, Aalborg University, 9220 Aalborg, Denmark; joz@energy.aau.dk

* Correspondence: mja@energy.aau.dk; Tel.: +45-9940-3375

check for

updates

Citation: Javidsharifi, M.; Pourroshanfekr Arabani, H.; Kerekes,

T.; Sera, D.; Spataru, S.V.; Guerrero,

J.M. Optimum Sizing of Photovoltaic-

Battery Power Supply for DroneBased Cellular Networks. Drones 2021, 5, 138. https://doi.org/ $10.3390 /$ drones 5040138

Academic Editor:

Diego González-Aguilera

Received: 29 September 2021

Accepted: 17 November 2021

Published: 22 November 2021

Publisher's Note: MDPI stays neutral with regard to jurisdictional claims in published maps and institutional affiliations.

Copyright: (c) 2021 by the authors. Licensee MDPI, Basel, Switzerland. This article is an open access article distributed under the terms and conditions of the Creative Commons Attribution (CC BY) license (https:/ / creativecommons.org/licenses/by/ $4.0 /)$.
Abstract: In order to provide Internet access to rural areas and places without a reliable economic electricity grid, self-sustainable drone-based cellular networks have recently been presented. However, the difficulties of power consumption and mission planning lead to the challenge of optimal sizing of the power supply for future cellular telecommunication networks. In order to deal with this challenge, this paper presents an optimal approach for sizing the photovoltaic (PV)-battery power supply for drone-based cellular networks in remote areas. The main objective of the suggested approach is to minimize the total cost, including the capital and operational expenditures. The suggested framework is applied to an off-grid cellular telecommunication network with drone-based base stations that are powered by PV-battery systems-based recharging sites in a rural location. The PV-battery system is optimally designed for three recharging sites with three different power consumption profiles with different peak and cumulative loads. Results show that the optimal design of the PV-battery system is dependent on geographical data, solar irradiation, and ambient temperature, which affect the output power of the PV system, as well as the power consumption profile, which affects the required number of PV panels and battery capacity.

Keywords: drones; base stations; cellular networks; photovoltaic system; battery

\section{Introduction}

Although the majority of the world's population has access to the internet through mobile networks, there is still a coverage gap in some rural and remote low-income areas [1-3]. Since the average cost of installing network infrastructure in remote areas is double the cost in urban areas, and due to a lower obtained revenue in rural areas, the deployment of fixed terrestrial mobile networks in remote areas is not cost-effective [1-6].

A new component in cellular networks is drones, or unmanned aerial vehicles (UAV), as small cellular base stations for covering scattered populations, especially in remote areas where the deployment of mobile networks is a burdensome task [2-4]. Compared to terrestrial cellular networks, UAV-aided networks are also more flexible. However, the major concerns in drone-based deployment are the limitations and constraints of the drones' batteries [2]. These batteries need to be charged in recharging sites connected to the electricity grid, which in turn, leads to an excess cost [3]. Nevertheless, in some cases, there is no access to a reliable electricity grid in rural areas [5]. To deal with these challenges, renewable energy sources (RESs), such as solar photovoltaic (PV) systems, can be deployed to supply the charging sites of UAVs in rural areas [3]. Besides being able to meet the needs 
of energy demand, RESs can also reduce the impact of fossil pollutants on the environment and guarantee socio-economic benefits for sustainable development [7,8]. Solar-powered UAV-based cellular telecommunication networks can be particularly significant for regions that have poor grid connectivity while being rich in solar resources (e.g., Sub-Saharan Africa or South Asia) [7].

When designing a PV-battery supply system for base stations in cellular telecommunication networks, dimensioning of the PV-battery system is a challenging issue since different factors, including capital expenditure (CAPEX), operational expenditure (OPEX), the intermittent nature of solar irradiance, varying traffic demand, power autonomy, and physical location constraints should be considered [7]. Power supplying of base stations in mobile networks through PV-battery systems has been investigated in the literature [9-20]. In [9], a cellular network that was powered via both the main electricity grid and a PV-battery system was studied, while the research in [10] was on mobile networks that solely depend on PV-battery power supply. A traffic-aware RES-powered base station was proposed in [11]. Some papers reviewed the sustainable deployment in mobile networks [12-15]. The focus of [16-18] was on modeling the performance of RES-based base stations to determine the size of the PV system and the storage device capacity based on Markovian models.

In order to size the components for an off-grid PV-battery system, the authors in [19] suggested the multi-objective wind-driven optimization (MO-WDO) algorithm. The objective of this paper was to optimize the number of PV panels as well as the capacity of the battery while "the annual total life cycle cost" was minimized. Reference [20] considered a genetic algorithm to solve the designing problem of a PV-battery system for the base station in an off-grid mobile network in Norcia, Italy, with the objective of simultaneously minimizing the investment and operational costs.

The focus of several papers in the literature was on energy management of future green mobile networks [7,19-28]. A review on opportunities, challenges, and perspectives of renewable energy-powered sustainable 5G network infrastructure was conducted in [6]. In [7], a multi-objective optimization framework was presented to minimize the total cost and maximize the power autonomy factor of a mobile network in which the base station is supplied via a PV-battery system or the electricity grid based on the suggested power dispatch strategy. The authors in [21] suggested a cost and energy-effective approach for a hybrid on-grid and solar-powered mobile network in a rural area.

Reference [22] suggested a "distributed online algorithm" to solve the energy management problem of an on-grid cellular network, and the objective was to optimize the data intake levels, energy sharing among base stations, transmit power, energy purchase from the grid, and the battery charging/discharging rate. In order to decrease on-grid energy consumption, [23] proposed "short and long-term reactive and proactive energy management" methods for heterogonous networks (HetNets). "A low complexity energy management" approach was presented in [24] for an on-grid macrocell base station, and the share of energy was with a centralized renewable farm. The goal of this paper was to decrease the grid energy cost.

An energy management approach for renewable-based base stations was suggested in [25]. In order to determine the optimum sizing of the system, the battery aging method was used, and reinforcement learning was applied to maximize battery life. The authors in [26] studied "the green energy provisioning problem" to decrease the CAPEX of renewable resource installations in HetNets while maintaining the quality of service (QoS) in the system. In [27], authors assessed the "power outage probability" of a renewable-based base station to decide on the PV-battery size, while in [28], the size of the battery was provided based on an analytical model of renewable fluctuations in each time scale.

It is recognized from the scope of these papers that almost all of them were focusing on the optimum sizing and energy management of renewable-based base stations in current mobile networks, i.e., without UAV deployment. However, as the importance of the application of UAVs in rural areas without access to a reliable electricity grid is discussed, 
the main objective of this paper is to optimally size the PV-battery power supply system for drone-based cellular networks to minimize the total cost. Applying UAVs as small cellular base stations is also beneficial in emergency or disaster situations, where the availability to the terrestrial networks is lost [4,29], or in big events such as Olympic Games or concerts where the number of mobile users increases for a short period and the installation of a fixed mobile network is not cost-effective $[4,30,31]$.

Compared to ground-based base stations, UAV-mounted small cellular base stations are able to cover specific sections of an area, have proper channel conditions towards users, and have the possibility of efficiently planning the UAVs' missions to schedule their coverage properly [6]. Consequently, an appealing choice for providing cellular networks in rural areas is small cellular base stations installed on UAVs [1-6]. Different aspects of UAV applications in cellular networks, including UAV mission planning, were studied in $[3,32-36]$ and reveal the significance of the presence of UAVs in future mobile networks.

In [3], energy-efficient mission scheduling of a UAV-based cellular network was proposed that was powered by a PV-Battery system. The main goal was minimizing the energy consumed by UAVs while cellular coverage was provided. In order to formulate the problem, mixed-integer linear programming was applied while a genetic algorithm was defined to solve the problem. The objective of [32] was minimizing the total costs of a UAV-based 5G architecture while considering the site's installation costs, the costs of solar panels, batteries, UAVs, and the optical ring among the installed sites. Each UAV flight was then scheduled either to cover an area or to recharge the UAV at the ground site.

The focus of [33] was on minimizing the energy consumed for moving the UAVs of a 5G deployment during the coverage of a set of rural areas. The authors claimed that the presented formulation and simulation framework was able to cover a set of areas, while minimizing the energy consumed by the UAVs. The main goal of [34] was the energy consumption management of a UAV-based cellular network that provided coverage to rural and low-income areas. The objective was to maximize the energy stored in the UAVs and in the charging sites, and the coverage of the territory was ensured through the scheduling of the UAV missions over space and time. A decomposition-based approach and a genetic algorithm were proposed to deal with the formulized problem. It was observed in [32-34] that the time slot of UAV mission planning was equal to one hour, which led to covering specific areas by UAVs for four consecutive hours, which is non-realistic and not applicable in real-world applications. However, in [3], the mission planning of UAVs was based on a 10-min time slot, which is more realistic.

The authors in [2] investigated the problem of minimizing the installation costs for a UAV-based cellular architecture adapted to serve rural areas. The UAV covering constraints, recharging action over time, and installation constraints on recharging sites were also considered. However, energy-efficient mission planning was not carried out in [2]. In [35], a trade-off between maximizing the throughput provided by the UAVs over a set of areas and minimizing OPEX was presented through a grid-connected microgeneration concept based on minimizing the energy bought from the electricity grid and maximizing the energy sold to the electricity grid in a UAV-based cellular network.

Due to the power consumption of the drones and the mission planning, the determination of optimal sizing of the power supply system of the drone-based cellular telecommunication networks is thoroughly different from conventional architecture [34].

The main contribution of this paper is to derive the power consumption profile of a UAV-based cellular telecommunication network based on the mission planning of UAVs in [3]. However, in [3], the constraints related to the power sources of recharging sites are not considered. Additionally, in [3], the authors did not design the PV-battery systems of the UAV recharging sites, and the results of [32] (namely the number of solar panels and batteries in each site) were used in their research. Moreover, the PVWatts calculator was used to exploit the historical energy production of solar panels. Consequently, a proper approach should be suggested for designing the PV-battery power supply system 
for recharging sites of UAVs, and a model for PV power generation should be applied such that the available PV generation can be calculated properly.

To achieve the above-mentioned goals, in this paper, we propose an optimization framework to minimize the total financial cost, including CAPEX and OPEX, of the PVbattery-powered off-grid cellular telecommunication network with drone-based base stations through sizing the PV-battery system based on the derived power consumption profiles for three recharging sites with different peak and cumulative values. We applied the particle swarm optimization (PSO) algorithm to find the best solution to the problem over a set of different scenarios.

The main contributions of this paper can be summarized as follows:

1. Proposing an optimization framework to minimize the total investment and operational costs of a PV-battery-powered off-grid UAV-based cellular telecommunication network in a rural area;

2. Extracting the power consumption profile for recharging stations in the UAV-based cellular telecommunication network based on the results of energy-efficient UAVs' mission planning in [3];

3. Developing a detailed model for PV power generation estimation that compromises PV panels' installation (azimuth and tilt) angles, ambient temperature, and PV module characteristics;

4. Considering the battery's technical constraints in the problem formulation and the battery's economic specifications in the system's operational cost.

The remainder of the paper is as follows: in Section 2, the UAV-aided cellular network configuration is presented. Additionally, the PV-battery energy supply model, as well as the energy consumption profile, are defined in this section. The problem formulation and the considered objective are discussed in Section 3. The suggested optimization algorithm is explained in Section 4. Simulation results are displayed in Section 5. The conclusions are investigated in Section 6.

\section{UAV-Aided Cellular Network}

Figure 1 shows the drone-based system structure in which two types of places, "areas" and "recharging sites", are considered. A section of the region that should always be covered by a UAV is called an "area", while a recharging site is a sector where PV-battery systems are established. The black line represents the radio link between the low level (LL) $5 \mathrm{G}$ base station on the UAV and the high level (HL) 5G ground-based base station [3].

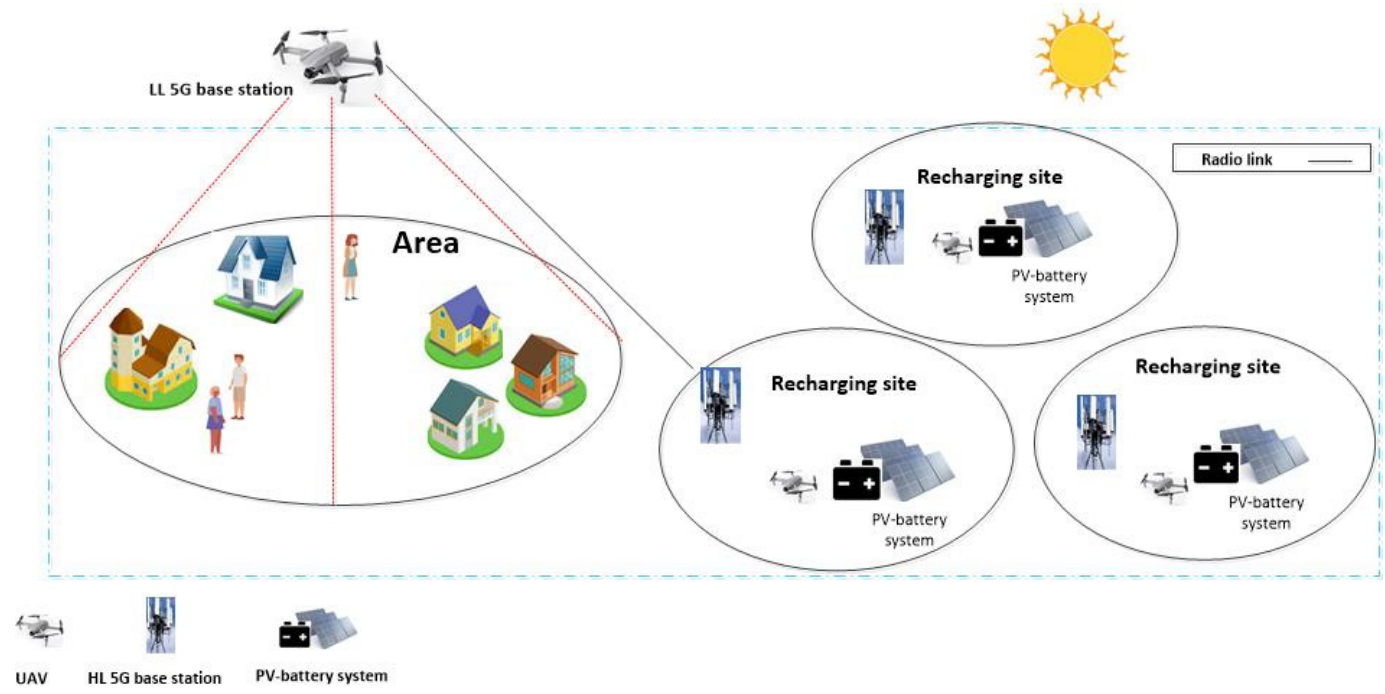

Figure 1. The configuration of an off-grid cellular telecommunication network with drone-based base stations powered by PV-battery systems. 
A battery is installed on each UAV, and when it is required, the drone can move to the recharging sites to be charged.

A set of actions are considered for the drones, including (a) STAY, the drone is in idle mode in a recharging site without consuming any energy; (b) Recharging, the drone batteries are recharging at a site; (c) Covering, the drone is covering an area; (d) Moving: the drone is moving from an area to another area or from an area to a recharging site or vice versa.

\subsection{PV-Battery System Modelling}

The selected mathematical PV model, as well as the considered battery model, are presented in this section.

The following generated PV power model is considered [7]:

$$
\begin{gathered}
P_{P V}^{t}=\frac{I^{t}(\theta, \gamma) \times P_{P V}^{P e a k} \times\left(1+d p\left(T_{C}^{t}-25\right)\right)}{1000} \\
I^{t}(\theta, \gamma)=I_{b}^{t}(\theta, \gamma)+I_{d}^{t}(\theta, \gamma)+I_{g}^{t}(\gamma) \\
T_{C}^{t}=T_{a}^{t}+\left[\frac{N O C T-20}{800}\right] \times I^{t}(\theta, \gamma)
\end{gathered}
$$

where $P_{P V}^{P e a k}$ is the PV system's rated power, $t$ is the number of the time slot, $I^{t}(\theta, \gamma)$ is the received solar irradiance by the PV system, $I_{b}^{t}(\theta, \gamma), I_{d}^{t}(\theta, \gamma)$ and $I_{g}^{t}(\gamma)$ are respectively the direct-beam, sky-diffuse, and ground-reflected components. $d p\left(\% /{ }^{\circ} \mathrm{C}\right)$ is the temperature coefficient which is considered -0.4 (for crystalline silicon solar cells technology [7]) in this paper. $T_{C}^{t}$ and $T_{a}^{t}$ are the cell and ambient temperatures, respectively. NOCT is the nominal operating cell temperature, which is considered $45^{\circ} \mathrm{C}$ [7]. The yearly solar irradiation of the considered case study is shown in Figure 2.

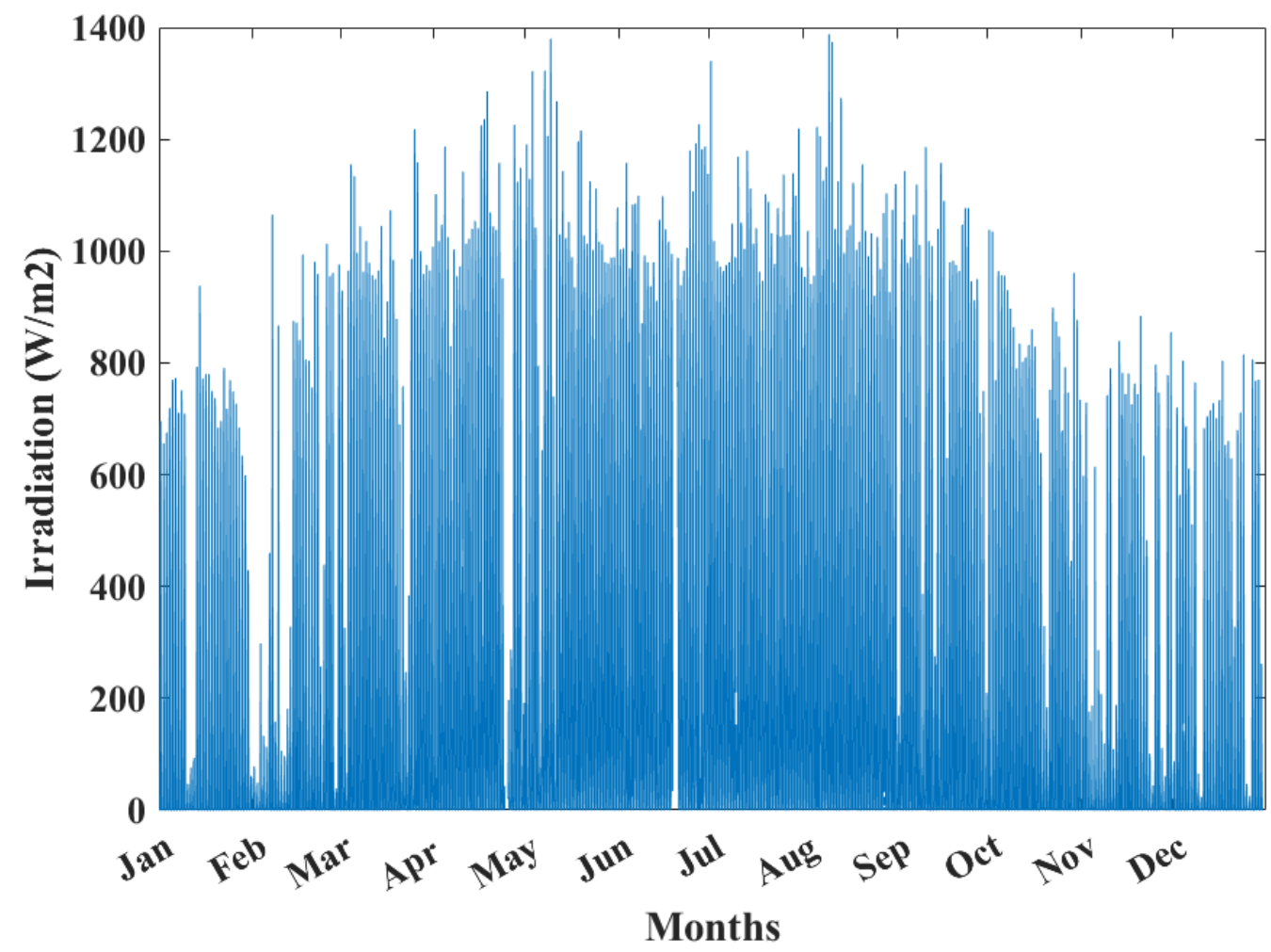

Figure 2. The yearly solar irradiation in the considered case study with 1-min resolution [36]. 
It is assumed that when a UAV is in a recharging site, the PV panels provide the required energy to charge the UAV's battery. If the generated power of PV panels cannot satisfy the required energy of the UAV's battery, then the batteries of the recharging sites are responsible for fulfilling the remaining power requirement of the UAV's battery. It should be mentioned that when no solar energy is available, for example, during nights or in cloudy weather, the stored energy in the batteries of the PV-battery system is used to satisfy the required energy for recharging the UAV's batteries [7].

The battery charge/discharge rate, as well as the state of charge (SOC) constraints, are considered as follows [7]:

$$
\begin{gathered}
S O C_{\text {Batt,min }} \leq S O C_{\text {Batt }}^{t} \leq S O C_{\text {Batt,Max }} \\
S O C_{\text {Batt }}^{t}=S O C_{\text {Batt }}^{t-1}+\frac{\eta_{C h} P_{C h}^{t} \cdot \Delta t}{C_{\text {Batt }}}+\frac{1}{\eta_{\text {Dch }} \cdot C_{\text {Batt }}} P_{D c h}^{t} \cdot \Delta t \\
P_{C h, \text { min }} \leq P_{C h}^{t} \leq P_{C h, \text { Max }} \\
P_{D c h, \text { min }} \leq P_{D c h}^{t} \leq P_{\text {Dch,Max }}
\end{gathered}
$$

where $S O C_{B a t t \text {,min }}$ and $S O C_{B a t t, M a x}$ are, respectively, the minimum and maximum $S O C$ of the battery, $S O C_{B a t t}^{t}$ is the battery $S O C$ at time $t, P_{C h}^{t}$ and $P_{D c h}^{t}$ are the battery charge and discharge rates at time $t, C_{B a t t}$ is the battery capacity, $\eta_{C h}$ and $\eta_{D c h}$ are, respectively, the battery charge and discharge efficiencies, and $\Delta t$ is the time slot. $P_{C h \text {, min }}$ and $P_{D c h \text {,min }}$ are the battery minimum charge and discharge rates, $P_{C h, M a x}$ and $P_{D c h, M a x}$ are the maximum battery charge and discharge rates, respectively.

\subsection{Energy Consumption Model}

The considered UAV energy consumption model of [3] is used in this paper to optimally design the PV-battery system of the recharging sites. The UAVs' actions, including recharging, covering, and moving, consume energy. The required energy for recharging the UAVs' battery is supplied by a PV-battery system in the recharging sites.

A rural location with approximately 40,000 inhabitants, containing small houses and without obstacles, was considered in [3]. The studied scenario is mapped in Figure 3. As observed, eight areas and three recharging sites are considered in which three places are simultaneously areas and recharging sites [3]. The power consumption profile of each recharging site was derived based on the mission planning of [3] and presented in Figure 3.

A time slot of $10 \mathrm{~min}$ for a one-day $(24 \mathrm{~h})$ time span was considered, which is matched with the battery capacity of available UAVs [3]. In Figure 3, the focus is on the first 24 time slots of the day, i.e., from $t_{1}$ to $t_{24}$; however, we assume that the mission planning of the UAVs is carried out in the first $8 \mathrm{~h}$ of the day, i.e., from 8 am to $4 \mathrm{pm}$ during which the solar energy production is at its highest values. 



Figure 3. Map of the studied scenario [3] and the derived power consumption profile of each recharging site.

\section{Problem Formulation}

\subsection{Objective Function}

In this section, the objective function is presented, which is minimizing the total financial costs of the PV-battery power system, including CAPEX and OPEX, from the mobile network operators (MNO) point of view:

$$
\begin{gathered}
\text { OF }=\min \left(\operatorname{Cost}_{\text {Total }}\right) \\
\operatorname{Cost}_{\text {Total }}=C A P E X+O P E X=C_{\text {Batt }} \cdot \operatorname{Cost}_{\text {Batt }}+P_{P V}^{\text {Peak }} \cdot \operatorname{Cost}_{P V}+\sum_{t=1}^{H} \operatorname{OPEX}_{\text {Batt }}^{t}
\end{gathered}
$$

where $\operatorname{Cost}_{P V}$ is the unit cost in $\$ / \mathrm{kW}, C_{B a t t}$ is the battery capacity, and $\operatorname{Cost}_{B a t t}$ is the unit cost in $\$$. $H$ is the horizon of study, OPEX $X_{\text {Batt }}^{t}$ is the battery operational cost, including the SOC-related $\left(\right.$ Cost $\left._{S O C}\right)$ and DoD-related $\left(\right.$ Cost $\left._{D o D}\right)$ costs [7]:

$$
\text { OPEX } X_{\text {Batt }}^{t}=\sum_{t=1}^{H} \operatorname{Cos} t_{S O C}^{t}+\sum_{t=1}^{H} \operatorname{Cos} t_{D o D}^{t}
$$




\subsection{Technical Constraint}

In addition to the battery constraints, the major technical constraint in sizing the PV battery power supply for drone-based cellular networks is the power balance equation as the following [7]:

$$
P_{P V}^{t}+P_{\text {Batt }}^{t} \geq P_{\text {Load }}^{t}
$$

where $P_{P V}^{t}$ and $P_{\text {Batt }}^{t}$ are the output power of PV panels and the battery charging/discharging power, respectively. $P_{\text {Load }}^{t}$ is the power consumption of the recharging site.

\section{Optimization Algorithm}

Particle swarm optimization (PSO) algorithm was considered in order to choose the optimal number of PV panels and battery capacities to charge the UAVs' batteries in recharging sites. The objective was to minimize the total cost by minimizing the number of PV panels and batteries of the recharging sites.

The advantages of metaheuristic algorithms over conventional mathematical methods are their simple implementation, freeness of gradient calculation, capability of avoiding local optimal points and reaching a global optimal solution, simplicity, and the capability of solving non-convex and nonlinear problems. These benefits led the researchers to apply metaheuristic algorithms in solving optimization problems in a variety of research areas [37-42].

According to the literature, the PSO algorithm is a powerful metaheuristic algorithm, which is efficient for solving optimization problems due to its stability, accuracy, simple formulation and implementation, and fast response [43-45]. The algorithm was first suggested by Kennedy and Eberhart in 1995 [43] and has been extensively applied by researchers in solving a variety of optimization problems [45]. Some current developments of the PSO algorithm were applied to solve problems in a variety of applications [46-48]. The authors in [46] combined an improved PSO algorithm with the continuous high-degree Bezier curve to solve the problem of smooth path planning for mobile robots. In order to tackle the problem of the optimal placement of motion sensors in smart homes and intelligent environments, [47] proposed a combination of the wale optimization algorithm (WOA) and PSO. An inverse kinematics calculation approach based on improved PSO was suggested in [48] for the inverse kinematic operation of general robots.

In the PSO algorithm, the behavior of a group of animals is imitated so that the animals in the group share their individual knowledge to find the best path to follow. The population in PSO is called the swarm, and each member of the swarm is named a particle. The algorithm starts with a random initial population. Each particle moves over the searching space while keeping in mind the best position it has experienced. Particles in the swarm share their best positions with each other and actively update their positions and velocities based on their own best-experienced position and the shared best positions. Accordingly, particles move towards optimal searching space during the searching procedure.

Assuming $f(x)$ as the objective function that is minimized, where $\vec{X}$ is the vector of design variables of $x$ and $d=1,2, \ldots, D$ is the counter of design variables where $D$ is the number of design variables. The counter of particles in the population is presented by $i=1,2, \ldots, N_{\text {swarm }}$, where $N_{\text {swarm }}$ is the number of particles or the size of the population. The counter of iterations in the algorithm procedure is defined by iter $=1,2, \ldots$, iter $_{\max }$, where iter $_{\max }$ shows the maximum number of iterations. The velocity $V_{i}^{(i t e r)}$ and position $X_{i}^{(i t e r)}$ of the $i$ th particle in the iterth iteration are updated based on the following:

$$
\begin{aligned}
& V_{i}^{(i t e r+1)}=\omega \cdot V_{i}^{i t e r}+c_{1} \cdot \operatorname{rand}_{1}(\cdot) \cdot\left(\text { Pbest }_{i}^{(i t e r)}-X_{i}^{(i t e r)}\right)+c_{2} \cdot \operatorname{rand}_{2}(\cdot) \cdot\left(\text { Gbest }^{(i t e r)}-X_{i}^{(i t e r)}\right) \\
& X_{i}^{(i t e r+1)}=X_{i}^{(i t e r)}+V_{i}^{(i t e r+1)} \\
& X_{i}^{(i t e r)}=\left[x_{i, 1}^{(i t e r)}, x_{i, 2}^{(i t e r)}, \ldots, x_{i, d}^{(i t e r)}\right]_{1 \times D}
\end{aligned}
$$


where $\omega$ is the inertia weight, $\operatorname{rand}_{1}(\cdot)$ and $\operatorname{rand}_{2}(\cdot)$ are random numbers in $[0,1]$. Pbest ${ }_{i}^{(i t e r)}$ is the best recorded previous experience of the ith particle in the iterth iteration. The best particle among the whole population (the position of the best particle corresponding to the minimum value of the objective function) is presented by Gbest ${ }^{(i t e r)} . c_{1}$ and $c_{2}$ are constant weights (mostly set equal to two in the literature [49]) of the stochastic acceleration terms that force each particle to move towards Pbest ${ }_{i}^{(i t e r)}$ and Gbest ${ }^{(i t e r)}$.

The steps of the applied PSO algorithm for solving the considered problem are as follows:

Step 1. Specify the geographical location, solar irradiation data, power consumption profile, battery specification, PV panel characteristics, number of design variables, the ranges of design variables, and the termination criterion.

Step 2. Generate initial solutions in the feasible design variable range based on the following:

$$
X=X_{\min }+\operatorname{rand}\left(X_{\max }-X_{\min }\right)
$$

where $X$ is an array of design variables considered as a solution including the PV system rated power, battery capacity, and battery charge and discharge rates, $X=\left[P_{P V}^{P e a k}, C_{B a t t}, P_{C h}^{t}, P_{D c h}^{t}\right], \quad t=1,2, \ldots, T . X_{\min }$ and $X_{\max }$ are, respectively, the lower and upper bounds of design variables, and rand is a random value in the range [0,1].

Step 3. Assess the initial particles. For each particle as a solution, the battery constraints are evaluated according to Equations (4)-(7) and the power balance constraint, Equation (10), and calculate the objective function in Equation (9).

Step 4 . Sort the initial particles based on the values of the objective function.

Step 5. Set iter $=1$.

Step 6. Determine Pbest ${ }_{i}^{(i t e r)}$ and Gbest ${ }^{(i t e r)}$ based on the sorted initial particles.

Step 7. Modify the positions of the particles based on Equations (12) and (13).

Step 8. For each modified particle, calculate the objective function after assessing the battery constraints according to Equations (4)-(7) and the power balance constraint in Equation (11).

Step 9. If any of the modified particles result in a lower value of the objective function Pbest ${ }_{i}^{(i t e r)}$, replace Pbest ${ }_{i}^{(i t e r)}$ by the modified particle. Otherwise, keep Pbest ${ }_{i}^{\text {iter })}$.

Step 10. Replace Gbest ${ }^{(i t e r)}$ by the modified particle if any of the modified particles result in a lower value of the objective function. Otherwise, keep Gbest ${ }^{\text {iter })}$.

Step 11. If the termination criterion (iter $=$ iter $_{\max }$ ) is satisfied, terminate the algorithm and go to Step 12; otherwise, set iter $=$ iter +1 and go to Step 6 .

Step 12. Print Gbest ${ }^{\left(\text {iter }_{\max }\right)}$, which includes the optimum number of PV panels, number of batteries, and the batteries' charging/discharging values in each time slot and the corresponding objective function value.

The proposed framework is illustrated in Figure 4. The specifications of the PV module and the battery and load profile data are the inputs of the proposed framework. For each combination of PV system rated power and battery capacity, the evaluation of technical constraints and the calculation of total cost are carried out based on the above-mentioned steps. Afterward, if the optimal total cost is achieved, the corresponding combination to the optimal total cost is considered as the optimal solution for the PV-battery system design. Otherwise, the combination of the PV-battery system is changed, and the new combination is evaluated by the PSO algorithm. The proposed framework is general and can be applied for designing PV-battery systems in any application. 


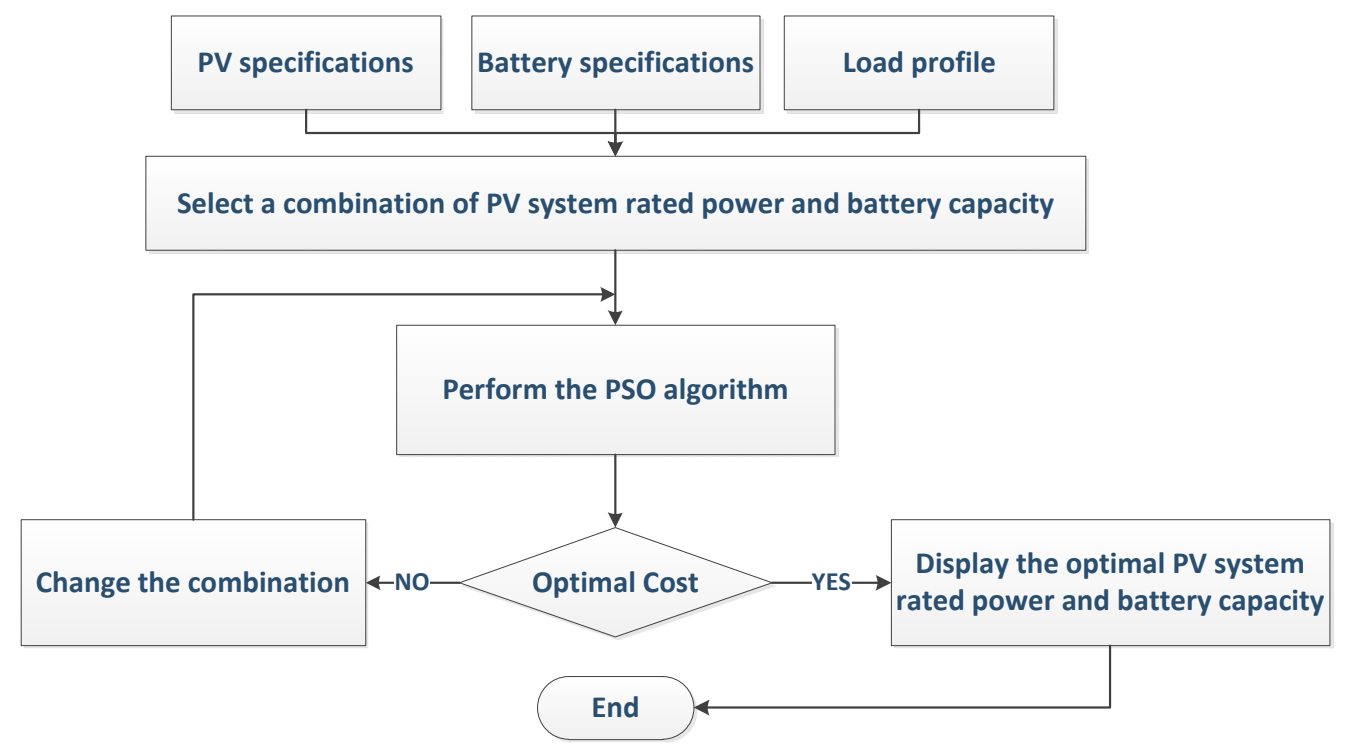

Figure 4. The proposed framework.

\section{Simulation Results}

In order to justify the effective performance of the suggested framework, a remote area with 40,000 inhabitants was considered (Figure 1), and the 24th of February was considered as the worst-case scenario because the solar irradiation is at its lowest values of the year (see Figure 2). The number of recharging sites is defined based on the "minimum cost algorithm" of [32]. The derived power consumption profile of each recharging site in Figure 3 is assumed as the load that should be satisfied based on (11).

The suggested approach was implemented in a MATLAB environment. The population size (the number of candidate solutions) and number of maximum iterations in the PSO algorithm were 50 and 200, respectively. The system variables and their range are presented in Table 1 . The results of the PSO algorithm are compared with the genetic algorithm (GA) in Table 2.

Table 1. The range of system variables.

\begin{tabular}{cccc}
\hline Variable & Symbol & Unit & Variable Range \\
\hline Peak PV power & $P_{P V}^{P e a k}$ & $\mathrm{~kW}_{\mathrm{p}}$ & $(0-10)$ \\
\hline Azimuth angle & $\theta$ & degree & $(-90-90)$ \\
\hline Tilt angle & $\gamma$ & degree & $(0-90)$ \\
\hline Battery capacity & $C_{\text {Batt }}$ & $\mathrm{kWh}$ & $(0-35)$ \\
\hline Battery state of charge & $S O C$ & $\%$ & $(10-90)$ \\
\hline
\end{tabular}

The optimum number of PV panels, battery capacity, and total cost of the system results for three recharging sites are outlined in Table 2. For the PSO algorithm, the power consumption of recharging Site 1 can be satisfied by $5.6 \mathrm{~kW}_{\mathrm{p}} \mathrm{PV}$ and $32 \mathrm{kWh}$ battery capacity that led to a total cost of USD 21,264. However, for the GA algorithm in Site 1, the installed PV was $6 \mathrm{~kW}_{\mathrm{p}}$, battery capacity was $32 \mathrm{kWh}$, and the total cost was USD 21,640. The optimal installed PV system for Sites 2 and 3 were, respectively, 4.8 and $4.4 \mathrm{~kW}_{\mathrm{p}}$ when applying the PSO algorithm. Additionally, the required battery capacities for these sites were 29 and $32 \mathrm{kWh}$, respectively. The value of the resulted total cost of the PV-battery system for site 3 (USD 20,136) was between that of Site 1 (USD 21,264) and Site 2 (USD 19,012). 
Table 2. The comparison between the results of PSO and GA algorithms: the optimal system design for each recharging site.

\begin{tabular}{|c|c|c|c|c|}
\hline & Recharging Site & $\begin{array}{c}\text { Installed PV } \\
\left(\mathbf{k W}_{\mathrm{p}}\right)\end{array}$ & $\begin{array}{c}\text { Battery } \\
\text { Capacity (kWh) }\end{array}$ & $\begin{array}{c}\text { Total Cost } \\
\text { (USD) }\end{array}$ \\
\hline \multirow{3}{*}{ PSO } & Site 1 & 5.6 & 32 & 21,264 \\
\hline & Site 2 & 4.8 & 29 & 19,012 \\
\hline & Site 3 & 4.4 & 32 & 20,136 \\
\hline \multirow{3}{*}{ GA } & Site 1 & 6 & 32 & 21,640 \\
\hline & Site 2 & 6.4 & 28 & 20,016 \\
\hline & Site 3 & 6 & 30 & 20,640 \\
\hline
\end{tabular}

When the GA algorithm was applied to solve the problem for Site 2, the required installed PV was $6.4 \mathrm{~kW}_{\mathrm{p}}$, and the battery capacity was $28 \mathrm{kWh}$. This PV-battery system led to a total cost of USD 20,016. For Site $3,6 \mathrm{~kW}_{\mathrm{p}}$ and $30 \mathrm{kWh}$ battery capacity were required to satisfy the load. The total cost, in this case, was USD 20,640.

To justify the values of Table 2, the feasible solutions of the optimization problem (minimizing the total cost) versus a variety of PV-battery system combinations based on the PV peak power from 1 to $10 \mathrm{kWp}$ with an interval of $0.4 \mathrm{kWp}$ and the battery capacity ranging from 1 to $35 \mathrm{kWh}$ with an interval of $1 \mathrm{kWh}$ are shown in Figures 5-7 for Sites 1, 2, and 3, respectively. According to these figures, it is observed that the PSO algorithm leads to more optimal solutions than GA, as shown in Table 2.

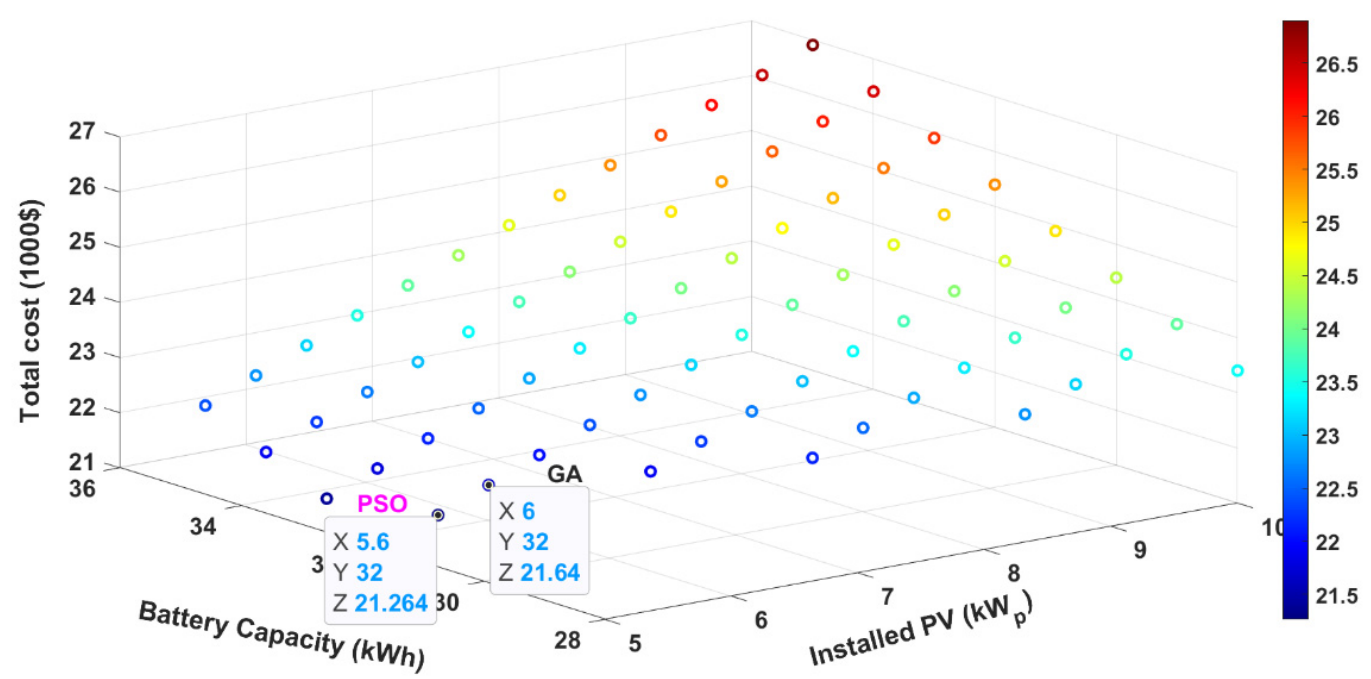

Figure 5. The comparison between PSO and GA algorithms: the feasible solutions of the optimization problem (minimizing the total cost) versus a combination of installed PV and battery capacity for recharging Site 1. 


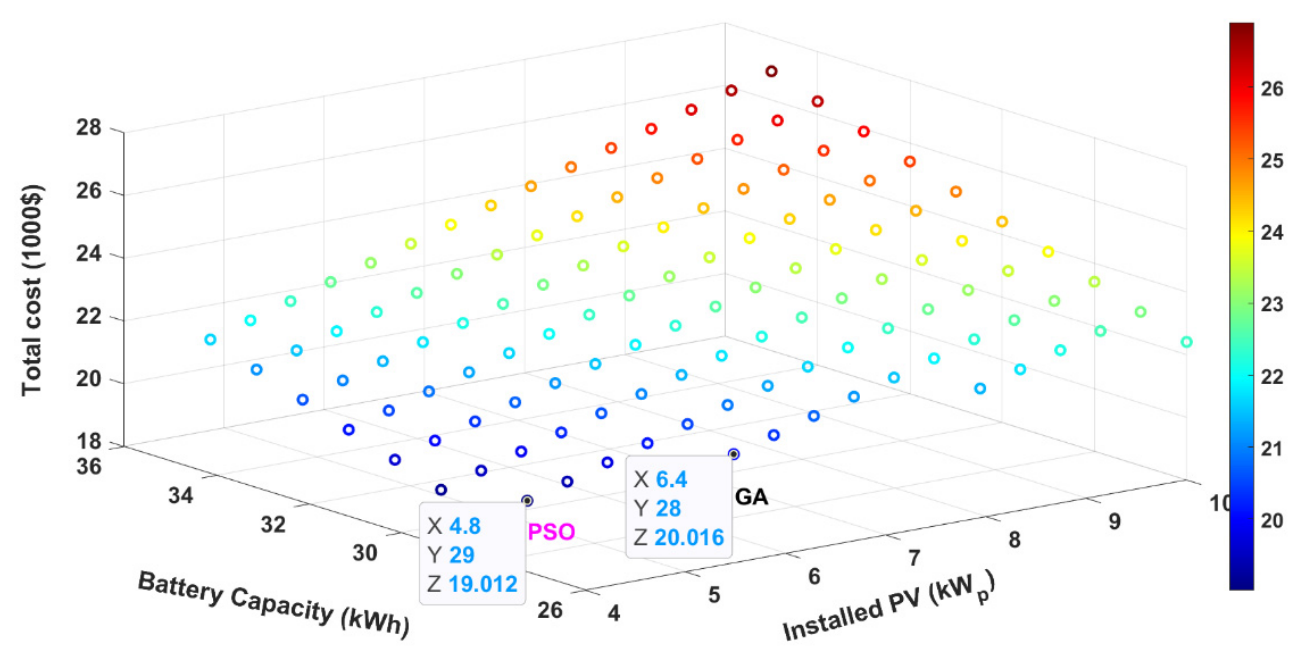

Figure 6. The comparison between PSO and GA algorithms: the feasible solutions of the optimization problem (minimizing the total cost) versus a combination of installed PV and battery capacity for recharging Site 2.

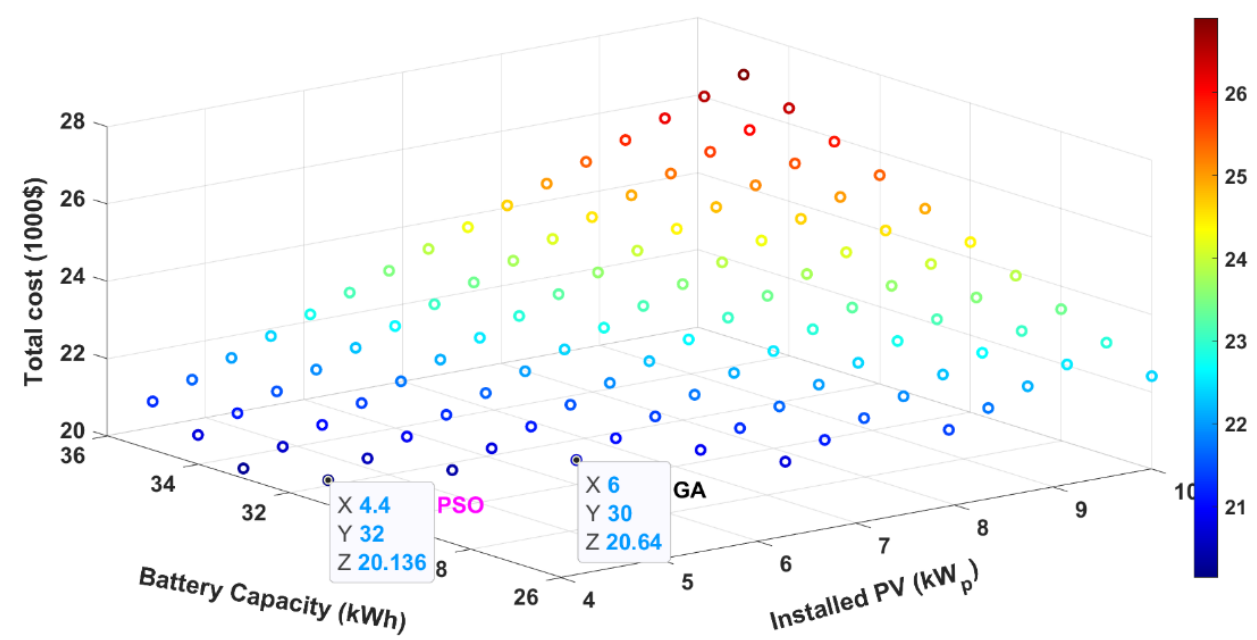

Figure 7. The comparison between PSO and GA algorithms: the feasible solutions of the optimization problem (minimizing the total cost) versus a combination of installed PV and battery capacity for recharging Site 3.

According to Table 2 and Figures 5-7, by comparing the results of PSO and GA algorithms, it can be concluded that the PSO algorithm leads to more cost-efficient solutions for the PV-battery system design of recharging sites.

The obtained results of the PSO algorithm for battery charging/discharging power, the load profile, and the PV system output power in recharging Sites 1, 2, and 3 are demonstrated in Figures 8-10, respectively. Figure 8 shows the battery charging/discharging power, the load profile, and the PV system output power in Site 1. It was observed that in time slots where the power consumption of the site is higher than PV power generation (i.e., time slots 6, 10, 14, 18, 22, 30, 34, 38, 42, and 46 for Site 1 where the UAVs are being recharged in the site) the energy stored in the battery is used to fulfill the load demand. Meanwhile, in the time slots where the available PV power generation was more than the power consumption, the excess power will be stored in the battery. 




Figure 8. The battery charging-discharging power, the load profile, and the PV system output power in recharging Site 1.

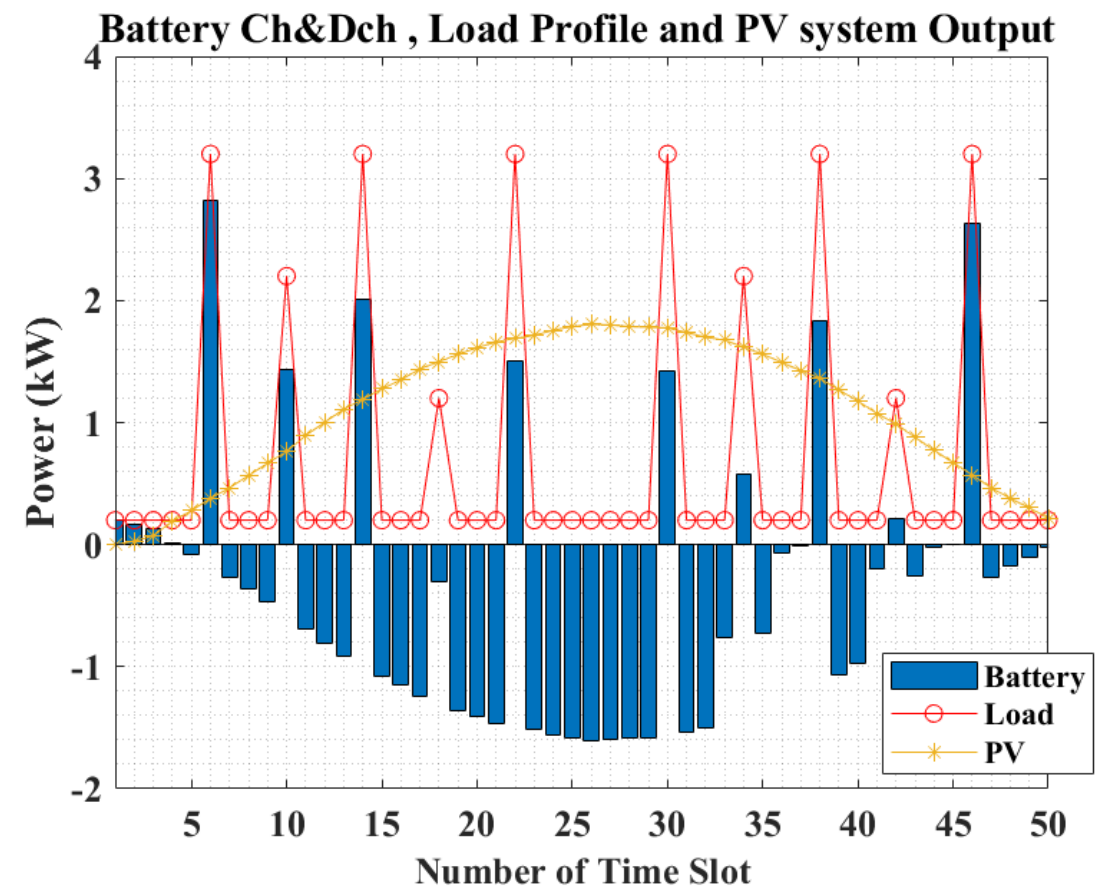

Figure 9. The battery charging-discharging power, load profile, and PV system output power in recharging Site 2. 


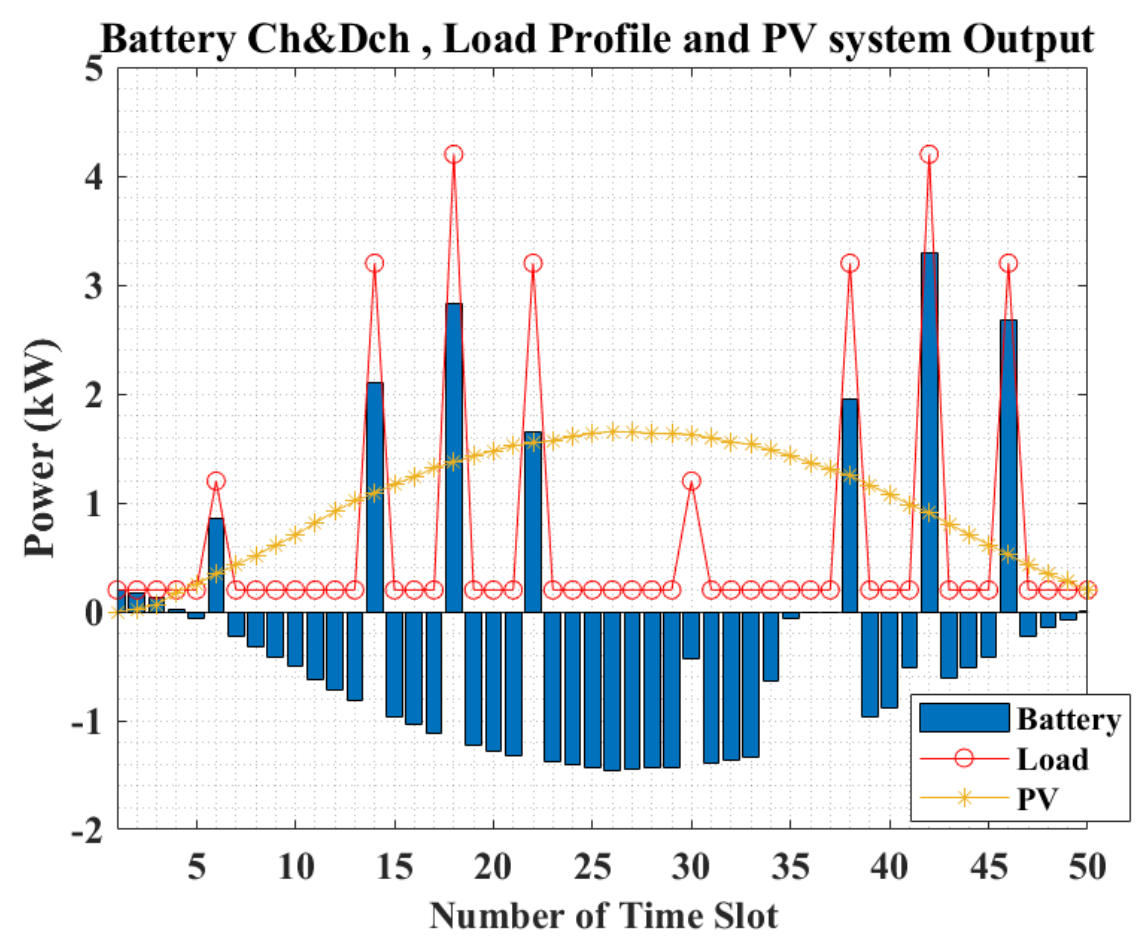

Figure 10. The battery charging-discharging power, load profile, and PV system output power in recharging Site 3.

The battery charging/discharging power, load profile, and PV system output power in recharging Site 2 are shown in Figure 9. By comparing Figures 8 and 9 , it is obvious that the peak load of Site $2(3.2 \mathrm{~kW})$ is lower than that of Site $1(6.2 \mathrm{~kW})$. Accordingly, in order to satisfy the load, a PV-battery system with lower capacity is required in Site 2, which leads to a lower total cost. However, both cumulative (the cumulative load of Site 1 is $42 \%$ more than that of Site 2) and peak loads affect the sizing of the PV-battery system, and the optimum PV-battery dimension is not linearly dependent on only the peak load.

In Figure 10, the battery charging/discharging power, load profile, and PV system output power in recharging Site 3 are illustrated. By comparing Figures 9 and 10, it can be concluded that although the cumulative load of Site 3 is 10\% lower than that of Site 2, since the peak power consumption of Site 3 is 33\% higher than that of Site 2, designing the PV-battery system leads to a higher cost for Site 3.

\section{Discussion and Future Research}

In order to design an optimal cost-efficient PV-battery power supply for recharging sites of a UAV-aided cellular telecommunication network in a rural area where there is no access to a reliable electricity grid, we proposed an optimization framework to minimize the total cost of the PV-battery system. The results of optimal mission planning in [3] are considered as the input of our research to achieve the load profile of each recharging site. However, for real-world applications, it is suggested that the mission planning of the UAVs and dimensioning of the PV-battery system be investigated as a united problem and be solved by an appropriate optimization methodology while considering the technical constraints from energy and telecommunication viewpoints simultaneously.

The investigated problem in this paper relies on the irradiation data and the load profile. The duration of the time slot of the extracted load profile in this paper is $10 \mathrm{~min}$. However, the available irradiation data for generation estimation are mostly with a onehour time resolution. By performing a broad search, irradiation data with a time resolution of 1-min for Milan, Italy, in 2017 [36] were found and used in this paper. However, it is more appropriate that the irradiation data of the studied rural area be used to achieve the most accurate solutions for the considered formulated problem. Another discussable 
point is that the achieved solutions are based on a daily load profile of 8-h of covering time of UAVs. To reach the solutions for real-world applications, it is suggested to use yearly data for a horizon of study of 10 years. In this case, the replacement and maintenance costs of components can also be considered, which leads us to be able to consider the payback period of the system. However, the required data and computational burden of the problem increase, and this needs more comprehensive considerations. PV-batterypowered UAV-aided telecommunication networks can also be implemented in urban areas where a reliable electricity grid is usually available. In this case, if the system is considered grid-connected, the mobile network operator can profit from selling the excess PV power generation to the main electricity grid instead of dumping surplus PV power.

\section{Conclusions}

Photovoltaic-battery systems for supplying demand in remote areas have been considered as a promising solution due to low operation costs, being eco-friendly, and easy availability. However, the main obstacle to the high applicability of PV-battery systems in remote areas is the high investment cost. Therefore, many aspects should be investigated before implementing PV-battery systems, such as PV system generation modeling to estimate the output power of PV system, PV panels and battery characteristics, geographical data, technical and economic criteria, and power dispatch strategy. In this paper, an optimization approach is presented to optimally size the PV-battery system for supplying the recharging sites of UAV-based cellular telecommunication networks in a rural off-grid area. The suggested methodology was applied on three UAV recharging sites with different peak and cumulative load profiles. It was observed that the required PV panel number and battery capacity for satisfying each load profile is dependent on both the peak and cumulative loads. The suggested framework was applied for sizing PV-battery systems in ground-based recharging sites for UAVs in cellular networks in off-grid applications. However, a scenario can be defined in which dimensioning of both onboard solar-powered UAVs and ground-based PV-battery systems for recharging sites is considered. In this case, the durability of UAVs' coverage mission increases, and consequently, the quality of service of the telecommunication network will be improved. Additionally, to investigate and compare the economics of different sources of energy, future work can focus on supplying the UAV-aided cellular telecommunication networks with other energy sources such as fuel cells.

Author Contributions: Conceptualization, M.J. and H.P.A.; methodology, M.J., H.P.A., and T.K.; software, M.J. and H.P.A.; validation, M.J., H.P.A. and T.K.; formal analysis, M.J.; investigation, M.J.; writing — original draft preparation, M.J.; writing—review and editing, T.K., D.S., S.V.S. and J.M.G.; supervision, T.K., D.S., S.V.S. and J.M.G. All authors have read and agreed to the published version of the manuscript.

Funding: This research was funded by the European Union's Horizon 2020 research and innovation programme under the Marie Sklodowska-Curie grant agreement No 812991. J.M.G. was supported by VILLUM FONDEN under the VILLUM Investigator Grant (no. 25920): Center for Research on Microgrids (CROM).

Institutional Review Board Statement: Not applicable.

Informed Consent Statement: Not applicable.

Data Availability Statement: Not applicable.

Conflicts of Interest: The authors declare no conflict of interest. 


\section{References}

1. Bahia, K.; Suardi, S. The State of Mobile Internet Connectivity 2019; Tech. Rep.; GSMA Connected Society: London, UK, 2019.

2. Chiaraviglio, L.; Amorosi, L.; Blefari-Melazzi, N.; Dell'Olmo, P.; Mastro, A.L.; Natalino, C.; Monti, P. Minimum Cost Design of Cellular Networks in Rural Areas with UAVs, Optical Rings, Solar Panels, and Batteries. IEEE Trans. Green Commun. Netw. 2019, 3, 901-918. [CrossRef]

3. Galán-Jiménez, J.; Moguel, E.; García-Alonso, J.; Berrocal, J. Energy-efficient and solar powered mission planning of UAV swarms to reduce the coverage gap in rural areas: The 3D case. Ad Hoc Netw. 2021, 118, 102517. [CrossRef]

4. Valiulahi, I.; Javidsharifi, M.; Virgili, M.; Masouros, C. D3. 1-Energy Models and Optimisation Framework: Phase 1. Available online: http:/ / painless-itn.com/wp-content/uploads/2020/10/D3.1_final.pdf (accessed on 12 November 2021).

5. Mozaffari, M.; Saad, W.; Bennis, M.; Nam, Y.-H.; Debbah, M. A tutorial on UAVs for wireless networks: Applications, challenges, and open problems. IEEE Commun. Surv. Tutor. 2019, 21, 2334-2360. [CrossRef]

6. Israr, A.; Yang, Q.; Li, W.; Zomaya, A.Y. Renewable energy powered sustainable 5G network infrastructure: Opportunities, challenges and perspectives. J. Netw. Comput. Appl. 2020, 175, 102910. [CrossRef]

7. Javidsharifi, M.; Pourroshanfekr, H.; Kerekes, T.; Sera, D.; Spataru, S.; Guerrero, J.M. Optimum Sizing of Photovoltaic and Energy Storage Systems for Powering Green Base Stations in Cellular Networks. Energies 2021, 14, 1895. [CrossRef]

8. Rokrok, E.; Javidsharifi, M.; Pourroshanfekr, H.; Javidsharifi, B. Adaptive Nonlinear Control Scheme for Three-Phase GridConnected PV Central Inverters. In Proceedings of the 29th International Power System Conference (PSC), Terhan, Iran, 27 October 2014; pp. 1-7.

9. Meo, M.; Zhang, Y.; Gerboni, R.; Marsan, M.A. Dimensioning the power supply of a LTE macro BS connected to a PV panel and the power grid. In Proceedings of the 2015 IEEE International Conference on Communications (ICC), London, UK, 8-12 June 2015; pp. 178-184.

10. Marsan, M.G.A.; Bucalo, G.; Di Caro, A.; Meo, M.; Zhang, Y. Towards Zero Grid Electricity Networking: Powering BSs with Renewable Energy Sources. In Proceedings of the 2013 IEEE International Conference on Communications Workshops (ICC), Budapest, Hungary, 9-13 June 2013; pp. 596-601.

11. Ahmed, F.; Naeem, M.; Ejaz, W.; Iqbal, M.; Anpalagan, A.; Kim, H.S. Renewable energy assisted traffic aware cellular base station energy cooperation. Energies 2018, 11, 99. [CrossRef]

12. Alsharif, M.H.; Kim, J.; Kim, J.H. Green and sustainable cellular base stations: An overview and future research directions. Energies 2017, 10, 587. [CrossRef]

13. Kusakana, K.; Vermaak, H.J. Hybrid renewable power systems for mobile telephony base stations in developing countries. Renew. Energy 2013, 51, 419-425. [CrossRef]

14. Aris, A.M.; Shabani, B. Sustainable power supply solutions for off-grid base stations. Energies 2015, 8, 10904-10941. [CrossRef]

15. Khare, V.; Nema, S.; Baredar, P. Status of solar wind renewable energy in India. Renew. Sustain. Energy Rev. 2013, 27, 1-10. [CrossRef]

16. Song, J.; Krishnamurthy, V.; Kwasinski, A.; Sharma, R. Development of a Markov-chain-based energy storage model for power supply availability assessment of photovoltaic generation plants. IEEE Trans. Sustain. Energy 2012, 4, 491-500. [CrossRef]

17. Leonardi, G.; Meo, M.; Marsan, M.A. Markovian Models of Solar Power Supply for a LTE Macro BS. In Proceedings of the 2016 IEEE International Conference on Communications (ICC), Kuala Lumpur, Malaysia, 22-27 May 2016; pp. 1-7.

18. Chamola, V.; Sikdar, B. Outage Estimation for Solar Powered Cellular Base Stations. In Proceedings of the 2015 IEEE International Conference on Communications (ICC), London, UK, 8-12 June 2015; pp. 172-177.

19. Ibrahim, I.A.; Sabah, S.; Abbas, R.; Hossain, M.J.; Fahed, H. A novel sizing method of a standalone photovoltaic system for powering a mobile network base station using a multi-objective wind driven optimization algorithm. Energy Convers. Manag. 2021, 238, 114179. [CrossRef]

20. Virgili, M.; Forysth, A.J.; James, P. A Multi-Objective Genetic Algorithm Methodology for the Design of Standalone Energy Systems. In Proceedings of the 2021 IEEE Design Methodologies Conference (DMC), Bath, UK, 14-15 July 2021 ; pp. 1-6.

21. Thakur, R.; Mishra, S.; Murthy, C.S.R. An energy and cost aware framework for cell selection and energy cooperation in rural and remote femtocell networks. IEEE Trans. Green Commun. Netw. 2017, 1, 423-433. [CrossRef]

22. Du, P.; Ran, L.; Zhai, D.; Ren, R.; Zeng, Q. Admm-based distributed online algorithm for energy management in hybrid energy powered cellular networks. IEEE Access 2019, 7, 83343-83353. [CrossRef]

23. Fletscher, L.; Suarez, L.; Grace, D.; Peroni, C.; Maestre, J. Energy-aware resource management in heterogeneous cellular networks with hybrid energy sources. IEEE Trans. Netw. Serv. Manag. 2019, 16, 279-293. [CrossRef]

24. Leithon, J.; Lim, T.J.; Sun, S. Cost-aware renewable energy management with application in cellular networks. IEEE Trans. Green Commun. Netw. 2018, 2, 316-326. [CrossRef]

25. Mendil, M.; De Domenico, A.; Heiries, V.; Caire, R.; Hadjsaid, N. Battery-aware optimization of green small cells: Sizing and energy management. IEEE Trans. Green Commun. Netw. 2018, 2, 635-651. [CrossRef]

26. Han, T.; Ansari, N. Provisioning green energy for base stations in heterogeneous networks. IEEE Trans. Veh. Technol. 2016, 65, 5439-5448. [CrossRef]

27. Chamola, V.; Sikdar, B. Power outage estimation and resource dimensioning for solar powered cellular base stations. IEEE Trans. Commun. 2016, 64, 5278-5289. [CrossRef] 
28. Ghiassi-Farrokhfal, Y.; Keshav, S.; Rosenberg, C.; Ciucu, F. Solar power shaping: An analytical approach. IEEE Trans. Sustain. Energy 2015, 6, 162-170. [CrossRef]

29. Renga, D.; Meo, M. Dimensioning renewable energy systems to power mobile networks. IEEE Trans. Green Commun. Netw. 2019, 3, 366-380. [CrossRef]

30. Jing, X.; Sun, J.; Masouros, C. Energy Aware Trajectory Optimization for Aerial Base Stations. IEEE Trans. Commun. 2021, 69, 3352-3366. [CrossRef]

31. Babu, N.; Papadias, C.B.; Popovski, P. Energy-Efficient 3D Deployment of Aerial Access Points in a UAV Communication System. IEEE Commun. Lett. 2020, 24, 2883-2887. [CrossRef]

32. Chiaraviglio, L.; Amorosi, L.; Blefari-Melazzi, N.; Dell'Olmo, P.; Natalino, C.; Monti, P. Optimal design of 5G networks in rural zones with UAVs, optical rings, solar panels and batteries. In Proceedings of the 2018 20th International Conference on Transparent Optical Networks (ICTON), Bucharest, Romania, 1-5 July 2018; pp. 1-4.

33. Amorosi, L.; Chiaraviglio, L.; D’Andreagiovanni, F.; Blefari-Melazzi, N. Energy-efficient mission planning of UAVs for 5G coverage in rural zones. In Proceedings of the 2018 IEEE International Conference on Environmental Engineering (EE), Milan, Italy, 12-14 March 2018; pp. 1-9.

34. Amorosi, L.; Chiaraviglio, L.; Galan-Jimenez, J. Optimal energy management of UAV-based cellular networks powered by solar panels and batteries: Formulation and solutions. IEEE Access 2019, 7, 53698-53717. [CrossRef]

35. Chiaraviglio, L.; D'andreagiovanni, F.; Choo, R.; Cuomo, F.; Colonnese, S. Joint optimization of area throughput and gridconnected microgeneration in uav-based mobile networks. IEEE Access 2019, 7, 69545-69558. [CrossRef]

36. Available online: http://www.solartech.polimi.it/activities/forecasting/dataset/ (accessed on 23 August 2021).

37. Javidsharifi, M.; Niknam, T.; Aghaei, J.; Mokryani, G.; Papadopoulos, P. Multi-objective day-ahead scheduling of microgrids using modified grey wolf optimizer algorithm. J. Intell. Fuzzy Syst. 2019, 36, 2857-2870. [CrossRef]

38. Javidsharifi, M.; Niknam, T.; Aghaei, J.; Mokryani, G. Multi-objective short-term scheduling of a renewable-based microgrid in the presence of tidal resources and storage devices. Appl. Energy 2018, 216, 367-381. [CrossRef]

39. Narimani, M.R.; Vahed, A.A.; Azizipanah-Abarghooee, R.; Javidsharifi, M. Enhanced gravitational search algorithm for multiobjective distribution feeder reconfiguration considering reliability, loss and operational cost. IET Gener. Transm. Distrib. 2014, 8, 55-69. [CrossRef]

40. Javidsharifi, M.; Niknam, T.; Aghaei, J.; Shafie-khah, M.; Catalão, J.P. Probabilistic Model for Microgrids Optimal Energy Management Considering AC Network Constraints. IEEE Syst. J. 2019, 14, 2703-2712. [CrossRef]

41. Mahboubi-Moghaddam, E.; Narimani, M.R.; Khooban, M.H.; Azizivahed, A.; Sharifi, M. Multi-objective distribution feeder reconfiguration to improve transient stability, and minimize power loss and operation cost using an enhanced evolutionary algorithm at the presence of distributed generations. Int. J. Electr. Power Energy Syst. 2016, 76, 35-43. [CrossRef]

42. Pourroshanfekr, H.; Javidsharifi, M.; Javidsharifi, B. Solving Non-convex Economic Dispatch with Valve Point Loading Effect using Imperialist Competitive Algorithm. Int. J. Manag. Perspect. 2015, 4, 41-45.

43. Eberhart, R.; Kennedy, J. Particle swarm optimization. In Proceedings of the IEEE International Conference on Neural Networks, Perth, WA, Australia, 27 November-1 December 1995; Volume 4, pp. 1942-1948.

44. Ahmadi, S.; Arabani, H.P.; Haghighi, D.A.; Guerrero, J.M.; Ashgevari, Y.; Akbarimajd, A. Optimal use of vehicle-to-grid technology to modify the load profile of the distribution system. J. Energy Storage 2020, 31, 101627. [CrossRef]

45. Al-Kazemi, B.; Habib, S. Complexity analysis of problem-dimension using PSO. In Proceedings of the WSEAS International Conference on Evolutionary Computing, Cavat, Croatia, 12-14 June 2006; pp. 45-52.

46. Song, B.; Wang, Z.; Zou, L. An improved PSO algorithm for smooth path planning of mobile robots using continuous high-degree Bezier curve. Appl. Soft Comput. 2021, 100, 106960. [CrossRef]

47. Nasrollahzadeh, S.; Maadani, M.; Pourmina, M.A. Optimal motion sensor placement in smart homes and intelligent environments using a hybrid WOA-PSO algorithm. J. Reliab. Intell. Environ. 2021. [CrossRef]

48. Yiyang, L.; Xi, J.; Hongfei, B.; Zhining, W.; Liangliang, S. A General Robot Inverse Kinematics Solution Method Based on Improved PSO Algorithm. IEEE Access 2021, 9, 32341-32350. [CrossRef]

49. Ridha, H.M.; Gomes, C.; Hazim, H.; Ahmadipour, M. Sizing and implementing off-grid stand-alone photovoltaic/battery systems based on multi-objective optimization and techno-economic (MADE) analysis. Energy 2020, 207, 118163. [CrossRef] 